\title{
Pattern of Fluid and Electrolyte Imbalance in Early Postoperative Period Following Temporary Ileostomy
} \author{
Dr. ASM Rezbanul Haque ${ }^{*}$, Dr. Md. Forhad Hossain ${ }^{2}$, Dr. Md. Firoz Mia ${ }^{3}$, Dr. Ismat Ara ${ }^{4}$, Dr. Samina Tasnim ${ }^{4}$, Dr.
} Md. Anisur Rahman ${ }^{5}$, Dr. Md. Mahfuzul Haque ${ }^{6}$, Dr. Bablu Kumar Saha ${ }^{7}$

\footnotetext{
${ }^{1}$ Registrar, Paediatric Surgery Department, Rangpur Medical College Hospital, Bangladesh

${ }^{2}$ Registrar, Surgery Department, Rangpur Medical College Hospital, Bangladesh

${ }^{3}$ Assistant Registrar, Surgery Department, Rangpur Medical College Hospital, Bangladesh

${ }^{4}$ IMO, Surgery Department, Rangpur Medical College Hospital, Bangladesh

${ }^{5}$ RS, Paediatric Surgery Department, Rangpur Medical College Hospital, Bangladesh

${ }^{6}$ Assistant Professor, Paediatric Surgery Department, Rangpur Medical College, Bangladesh

${ }^{7}$ Associate Professor, Paediatric Surgery Department, Rangpur Medical College, Bangladesh
}

DOI: $\underline{10.36347 / \text { sjams.2020.v08i11.006 }}$

| Received: 12.10.2020 | Accepted: 27.10.2020 | Published: 09.11.2020

*Corresponding author: ASM Rezbanul Haque

Background: There are complications of ileostomy development, including fluid and electrolyte imbalance. Although predictors of high morbidity have been established by studies, readmission rates remain high. Objective: In this study, our main goal is to evaluate the patter of fluid and electrolyte imbalance in the early postoperative period of a temporary ileostomy. Method: This retrospective study was conducted at a tertiary medical college and hospital from January 2017 to December 2019. A total of 120 patients with ileostomy creation, were included in this study. We obtained the medical records and compiled data of the patients admitted to the hospital. Results: In this study, $60 \%$ of patients were male and $40 \%$ were female. Maximum (40\%) patients were between 40-49 years of age group. Among 120 patients, 49 were readmitted due to fluid and electrolyte abnormalities and 27 were readmitted due to other diagnoses. Only the use of antidiarrheals and neoadjuvant therapy remained important after multivariate review. Conclusion: Our study concluded that the use of a patient should be carefully checked at home postoperatively. Our study also recommends the thought of shirking of ileostomy creation or diverse release standards for patients at risk. Postoperative findings showed that stoma checking after release may help decrease rehospitalizations for liquid and electrolyte anomalies after ileostomy creation. Antidiarrheals might be a marker for patients in danger for patter fluid and electrolyte imbalance.

Keywords: ileostomy development, electrolyte imbalance, patients, patter fluid.

Copyright $\odot 2020$ The Author(s): This is an open-access article distributed under the terms of the Creative Commons Attribution 4.0 International License (CC BY-NC 4.0) which permits unrestricted use, distribution, and reproduction in any medium for non-commercial use provided the original author and source are credited.

\section{INTRODUCTION}

The invention of an ileostomy is an ordinarily performed strategy in the field of colorectal medical procedures. Since Brooke altered the strategy in 1952 [1], ileostomy has become the essential choice for fecal redirection in numerous cases. The signs for an occupying ileostomy are different and incorporate both crisis and elective procedures [2-7]. Ileostomy development is demonstrated for entrail ischemia, gut hindrance, fiery gut ailment, malignant growth, and tasks with an expanded danger of anastomotic hole. For patients who go through proctectomy for the rectal disease after preoperative chemotherapy and radiation, fecal preoccupation has not been found to influence the occurrence of anastomotic hole; rather, it diminishes the related morbidity [8, 9]. Still, production of an ileostomy includes its own perioperative and postoperative difficulties; a rate of $20-60 \%$ was accounted for in the literature [10-12]. These confusions incorporate stoma stenosis, retraction, necrosis, small bowel obstruction, skin excoriation, and fluid and electrolyte abnormalities. There are presently not many realized danger components to foresee which patients are at expanded danger for clinic readmission following ileostomy creation. Emergency clinic readmission inside 30 days after the medical procedure is getting expanded consideration as an exorbitant and conceivably preventable difficulty after a medical procedure. A few investigations have recognized high stoma yield as an antecedent to parchedness or renal dysfunction [13]. These morbidities have an announced rate somewhere in the range of 1 and $17 \%$ and are liable for $4-43 \%$ of readmissions for ileostomy patients [1316]. Although a few examinations have distinguished components that may anticipate this dreariness, 
readmission rates stay high. This study aims to evaluate the patter of fluid and electrolyte imbalance in the early postoperative period of a temporary ileostomy. This might help us to create strategies that decrease readmission for fluid and electrolyte abnormalities.

\section{OBJECTIVe}

In this study, our main goal is to evaluate the patter of fluid and electrolyte imbalance in the early postoperative period of a temporary ileostomy.

\section{Methodology}

\begin{tabular}{|l|l|}
\hline Type of study & Retrospective study \\
\hline Place of study & Tertiary medical college and hospital \\
\hline Study period & January 2017 to December 2019 \\
\hline Study population & A total of 120 patients with ileostomy creation, were included in this study \\
\hline Sampling technique & Purposive sampling \\
\hline
\end{tabular}

\section{METHOD}

- We obtained the medical records and compiled retrospective data chart of 120 patients with temporary ileostomy creation, admitted to the hospital. All data were received through the complete written consent of the patients and the hospital.

\section{STATISTICAL ANALYSIS}

- Collected data was collated and appropriate statistical analysis was done using a computer- based SPSS (Statistical Program for scientific study) package. All p values were two-tailed, and $p<0.05$ was the criterion for statistical significance.

\section{RESULTS}

Table-1 shows the age distribution of the patients; the range was 20-79 years. Maximum (40.7\%) patients were in the age group of $40-49$ years. The following table is given below in detail:

Table-1: Distribution of patients according to age $(n=120)$

\begin{tabular}{|l|l|}
\hline Age (years) & Percentage (\%) \\
\hline $20-29$ & $11.6 \%$ \\
\hline $30-39$ & $13.8 \%$ \\
\hline $40-49$ & $40.7 \%$ \\
\hline $50-59$ & $21.1 \%$ \\
\hline $60-69$ & $8.33 \%$ \\
\hline $70-79$ & $4.47 \%$ \\
\hline
\end{tabular}

Figure- 1 shows the gender distribution of the patients where $60 \%$ of patients were male, $40 \%$ were female. The following figure is given below in detail:

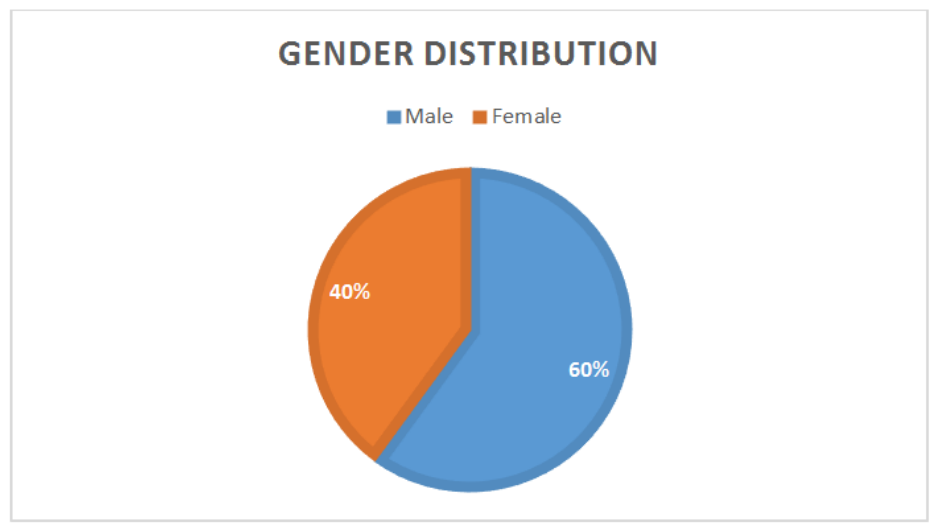

Fig-1: Gender distribution of the patients

The Table- 2 shows diagnosis reports and sign and symptoms of the patients where most of the patients (59) had Inflammatory bowel disease, 40 had cancer, followed by 5 had colonic inertia, 2 had an anastomotic leak, 4 had diverticulitis, 2 had a perineal fistula, 3 had a colonic obstruction, 4 had Rectal prolapse and 1 had Colonic stricture. The following table is given below in detail: 
Table-2: Sign and symptoms of the patients

\begin{tabular}{|l|l|}
\hline Sign and symptoms & Number of patients \\
\hline Cancer & 40 \\
\hline Inflammatory bowel disease & 59 \\
\hline Colonic inertia & 5 \\
\hline Anastomotic leak & 2 \\
\hline Diverticulitis & 4 \\
\hline Perineal fistula & 2 \\
\hline Colonic obstruction & 3 \\
\hline Rectal prolapse & 4 \\
\hline Colonic stricture & 1 \\
\hline
\end{tabular}

Figure-2 shows the type of ileostomy of the patients according to the diagnosis findings where 96 patients had loop ileostomy and 24 patients had end ileostomy.

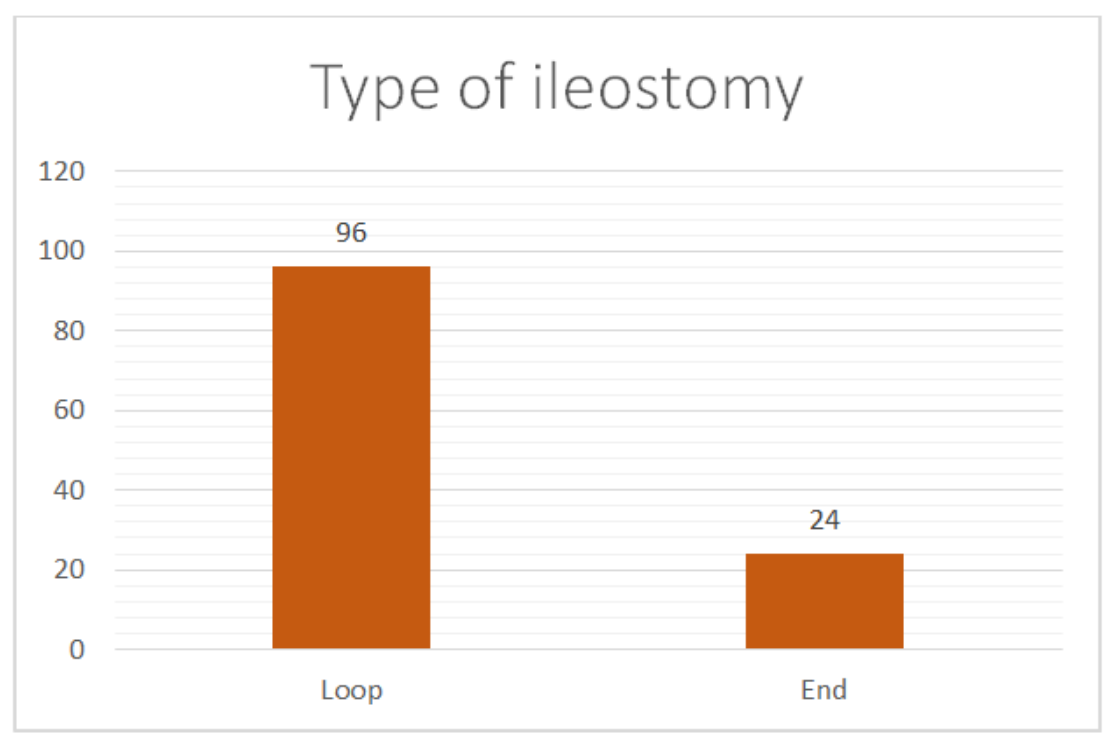

Fig-2

The Table-3 shows all medications at discharge time of patients also the postoperative findings of the readmission cause of patients. Among
120 patients, 49 had fluid and electrolyte imbalance at the early postoperative time and 27 had other diagnoses for the readmission.

Table-3: Medications at discharge and readmission of patients

\begin{tabular}{|l|l|}
\hline Variables & Number of patients \\
\hline Medications at discharge & \\
\hline Narcotics & 92 \\
Fiber & 18 \\
Anti-diarrheals & 65 \\
Ileostomy reversal & 103 \\
\hline Readmission & \\
\hline For any diagnosis & 27 \\
Fluid and Electrolyte abnormalities & 49 \\
\hline
\end{tabular}

\section{DISCUSSION}

High stoma yield is portrayed by expanded loss of water and sodium in the fecal waste, which may prompt hyponatremia, dehydration, and hyperaldosteronism [17]. Hypomagnesemia might be available in the early postoperative period, yet it is more continuous in patients with longstanding ileostomies $[17,18]$. Some of the basic reasons for high ostomy yield are proximal stomas, short bowel syndrome (less than $200 \mathrm{~cm}$ of small bowel remaining), intraabdominal sepsis, enteritis, medications, and small bowel obstruction. Beck-Kaltenbach et al., indicated that ileostomy development is a danger factor for renal impairment [13]. Most of the patients gave just moderate abatements in GFR that were not clinically huge; nonetheless, $30 \%$ of the patients were found to have renal disappointment auxiliary to lack of hydration, requiring readmission $[13,17]$. Our findings 
are consistent with other studies: readmission happened most oftentimes inside a multi-week of release, like the timetable depicted as the basic time frame for intricacies, happening between postoperative day two and eight by Tang et al., [19] We examined preoperative conditions, perioperative course, and clinical status at release (drugs, electrolyte balance, stoma yield, and pee yield). The majority of the factors were not related to readmission, which matches different investigations that propose readmission after the colorectal medical procedure may not be anticipated by postoperative clinical information [20]. Other examinations trait early release to early readmission, since patients may give difficulties at home rather than while hospitalized [20]. Anti-diarrheals, for example, loperamide, have been appeared to diminish day by day misfortunes of sodium and potassium, forestalling electrolyte imbalances. In our investigation, the remedy against diarrheal at release was related to readmission because of parchedness. Even though our investigation neglected to show a relationship between high stoma yield and readmission rate, the utilization of antidiarrheals might be a marker for high stoma yield. We assessed careful variables including kind of ileostomy, manifestations, and the reason for the readmission of the patients. Pastry specialist et al. recommended that patients with high stoma yield may be overseen at home by confining the volume of oral ingestion and the utilization of glucose-electrolyte arrangements and against motility prescriptions. Our study is limited by its retrospective design. Data was gathered from clinical records of hospitalizations, however, didn't consider patients that may have gotten treatment at different organizations, workplaces, or home visits.

\section{CONCLUSiON}

It can be concluded that the use of antidiarrheals might be a marker for patients in danger for patter fluid and electrolyte imbalance; these patients ought to be carefully checked at home. Our investigation recommends the thought of shirking of ileostomy creation or diverse release standards for patients at risk. Postoperative findings showed that stoma checking after release may help decrease rehospitalizations for liquid and electrolyte anomalies after ileostomy creation. Early intervention and prevention are better strategies, it is indistinct which components should be remembered for a postoperative consideration pathway to accomplish ideal results.

\section{REFERENCES}

1. Brooke BN. The management of an ileostomy, including its complications. Lancet. 1952; 2:102104.

2. Tan WS, Tang CL, Shi L, Eu KW. Meta-analysis of defunctioning stomas in low anterior resection for rectal cancer. Br J Surg. 2009; 96:462-472.
3. Wexner SD, Taranow DA, Johansen OB, Itzkowitz F, Daniel N, Nogueras JJ, Jagelman DG. Loop ileostomy is a safe option for fecal diversion. Diseases of the colon \& rectum. $1993 \mathrm{Apr}$ 1;36(4):349-54.

4. Matthiessen $P$, Hallböök $\mathrm{O}$, Rutegård J, Simert G, Sjödahl R. Defunctioning stoma reduces symptomatic anastomotic leakage after low anterior resection of the rectum for cancer: a randomized multicenter trial. Ann Surg. 2007; 246:207-214.

5. Winslet MC, Barsoum G, Pringle W, Fox K, Keighley MR. Loop ileostomy after ileal pouchanal anastomosis: is it necessary? Dis Colon Rectum. 1991; 34:267-270.

6. Metcalf AM, Dozois RR, Beart RW Jr, Kelly KA, Wolff BG. Temporary ileostomy for ileal pouchanal anastomosis: function and complications. Dis Colon Rectum. 1986; 29:300-303.

7. Messaris E, Sehgal R, Deiling S, Koltun WA, Stewart D, McKenna K, Poritz LS. Dehydration is the most common indication for readmission after diverting ileostomy creation. Diseases of the colon \& rectum. 2012 Feb 1;55(2):175-80.

8. Matthiessen P, Hallböök O, Rutegård J, Simert G, Sjödahl R. Defunctioning stoma reduces symptomatic anastomotic leakage after low anterior resection of the rectum for cancer: A randomized multicenter trial. Ann Surg, 2007; 246: 207-214

9. Wong NY, Eu KW. A defunctioning ileostomy does not prevent clinical anastomotic leak after a low anterior resection: A prospective, comparative study. Diseases of the colon rectum, 2005; 48:2076-2079.

10. Debongnie JC, Phillips SF. Capacity of the human colon to absorb fluid. Gastroenterology, 1978; 74:698-703.

11. Harris DA, Egbeare D, Jones S, Benjamin H, Woodward A, Foster ME. Complications and mortality following stoma formation. Ann R Coll Surg Engl, 2005; 87:427-431.

12. Robertson I, Leung E, Hughes D, Spiers M, Donnelly L, Mackenzie I, Macdonald A. Prospective analysis of stoma- related complications. Colorectal Disease. 2005 May;7(3):279-85.

13. Beck-Kaltenbach N, Voigt K, Rumstadt B. Renal impairment caused by temporary loop ileostomy. Int J Colorectal Dis, 2011; 26:623-626

14. Bax TW, McNevin MS. The value of diverting loop ileostomy on the high-risk colon and rectal anastomosis. Am J Surg, 2007; 193:585-588.

15. Chun L, Haigh $\mathrm{P}$, Tam M, Abbas $\mathrm{M}$. Defunctioning loop ileostomy for pelvic anastomoses: predictors of morbidity and nonclosure. Diseases of the colon rectum, 2012; 55:167-174.

16. Messaris E, Sehgal R, Deiling S, Koltun WA, Stewart D, McKenna K, Poritz LS. Dehydration is 
the most common indication for readmission after diverting ileostomy creation. Diseases of the colon rectum, 2012; 55:175-180.

17. Shabbir J, Britton DC. Stoma complications: a literature overview. Colorectal disease, 2010; 12:958-964.

18. Baker ML, Williams RN, Nightingale JMD. Causes and management of a high-output stoma. Colorectal disease, 2011; 13:191-197.
19. Tang CL, Yunos A, Leong APK, Seow-Choen F, Goh HS. Ileostomy output in the early postoperative period. Br J Surg, 1995; 82:607.

20. Kiran R, Delaney C, Senagore A, Steel M, Garafalo T, Fazio V. Outcomes and prediction of hospital readmission after intestinal surgery. J Am Coll Surg, 2004; 198:877-883. 